\title{
Radiografias periapicais prévias ao tratamento ortodôntico
}

\author{
Alberto Consolaro
}

As radiografias panorâmicas, assim como são mais conhecidas as ortopantomografias, não são indicadas para o diagnóstico de reabsorções dentárias. Quando detectadas nestas radiografias, tratam-se de casos avançados de reabsorção com grande perda de estrutura dentária. As reabsorções pequenas e médias não são detectáveis nas radiografias panorâmicas.

Estas afirmações inferem que as radiografias panorâmicas nas documentações ortodônticas têm vários objetivos, mas entre estes não deve ser incluído o diagnóstico prévio de reabsorções dentárias pré-existentes.

As reabsorções dentárias, no mundo ocidental, têm uma prevalência entre 6 e 10\% dentre as pessoas que nunca realizaram qualquer tipo de tratamento ortodôntico. Em termos clínicos, isto pode ser assim traduzido: em cada 100 pacientes ortodônticos, 6 a 10 têm reabsorções dentárias em um ou mais dentes, podendo gerar problemas durante o tratamento.

No tratamento ortodôntico a severidade das reabsorções pré-existentes pode aumentar com as reações teciduais induzidas pelo movimento dentário, pelo aumento local dos níveis de mediadores e/ou então pelo tempo transcorrido de 1 a 2 anos. Sem uma radiografia adequada e prévia de diagnóstico das reabsorções dentárias como poder-se-á alegar, especialmente nos laudos periciais, que a origem destas reabsorções pré-existentes não têm relação direta e primária com o tratamento ortodôntico.
As radiografias periapicais são as mais indicadas para o diagnóstico de alterações como fraturas radiculares, calcificações pulpares, metamorfose cálcica da polpa, cárie, periapicopatias e outras alterações exclusivas dos dentes, incluindo-se as reabsorções. Em outras palavras, no planejamento ortodôntico deve-se incluir a análise minuciosa de radiografias periapicais de todos os dentes. O objetivo é diagnosticar alterações dentárias pré-existentes não detectáveis pelas radiografias panorâmicas e assim evitar complicações durante o tratamento ortodôntico. As radiografias periapicais de todos os dentes antes do tratamento ortodôntico representam, em seu conjunto, uma das formas mais eficientes de prevenir-se de problemas associados às reabsorões dentárias durante o tratamento ortodôntico.

As radiografias prévias ao tratamento ortodôntico não devem se restringir aos incisivos superiores e inferiores, pois estes não podem servir de referência para o diagnóstico de ocorrência, e nem de severidade, das reabsorções nos demais dentes.

Há a algum tempo atrás, eram comuns afirmações como: se houver uma percepção de algum problema em alguns dentes ou regiões nas radiografias panorâmicas, solicita-se então radiografias periapicais dos dentes suspeitos. Nas radiografias panorâmicas, porém, não é possível detectar imagens ou percepções de reabsorções dentárias pequenas e médias.

Estas abordagens são muito importantes para evitar perdas dentárias durante e após o tratamento 
ortodôntico, decorrentes de reabsorções internas, reabsorções por substituição, reabsorções cervicais externas e outras que já pré-existiam. As radiografias periapicais no planejamento ortodôntico evitam que diagnósticos não realizados adequada e previamente possam ser a causa de condenações processuais de ortodontistas. O diagnóstico prévio ao tratamento ortodôntico de problemas bucais e dentários é responsabilidade de qualquer profissional da área odontológica.

O ortodontista, como os demais especialistas, deve ter conhecimento suficiente para detectar ou suspeitar da perda da normalidade e encaminhar o paciente para outro especialista esclarecer o problema supostamente detectado. Também como responsável de diagnóstico de lesões e reabsorções dentárias pré-existentes ao tratamento ortodôntico, está o radiologista que assinou o laudo emitido. $\mathrm{Na}$ relação entre ortodontista e radiologista deve imperar a cooperação, ética e complementariedade, para que a competência tenha lugar. A interação constante ortodontista-radiologista e a emissão de laudo descritivo das radiografias auxiliam, em muito, o planejamento ortodôntico e promovem a divisão de responsabilidades nos diagnósticos a serem realizados, antes do início do tratamento ortodôntico.

Em forma de insight algumas perguntas ficam sem respostas e podem induzir reflexões para novas pesquisas e abordagens sobre o tema:

1) Por que não há pesquisas de casuísticas ortodônticas comparando os tratamentos realizados e suas conseqüências, como as reabsorções radiculares, sem e com a obtenção e análise de radiografias periapicais prévias em suas documentações?

2) Nos processos judiciais contra os ortodontistas, quantos casos estão relacionados com as reabsorções dentárias e, destas, quantas poderiam ser diagnosticadas por radiografias periapicais prévias e não o foram?

3) Em casuísticas ortodônticas exclusivamente com radiografias panorâmicas e em outras com radiografias periapicais prévias, qual foi a prevalência das reabsorções dentárias detectadas previamente?
4) Quais as implicações econômicas nas planilhas de custo do tratamento ortodôntico se as radiografias periapicais prévias forem adotadas como procedimento de rotina? Qual a relação custo-benefício para o paciente e para o profissional?

5) Quais razões os profissionais que não solicitam radiografias periapicais prévias alegam para não adotarem esta conduta:

a) Falta de conhecimento de suas vantagens?

b) Receio de que o aumento de custo da documentação iniba a realização do tratamento ortodôntico por parte do paciente?

c) Falta de uma cultura profissional de prevenção em relação a processos judiciais?

d) Não aprenderam este procedimento em sua formação ortodôntica e mudar hábitos e cultura representa uma prática difícil?

Quando pensamos em pesquisa, quase sempre, nos remetemos a laboratórios e equipamentos sofisticados. Não necessariamente. A busca pelo conhecimento e pelo avanço das práticas medicoodontológicas também passa pela checagem das vantagens e desvantagens de protocolos de conduta, diagnóstico e tratamento. Infelizmente, em muitas áreas do conhecimento e da prática médico-odontológica, observa-se a falta de padronização e a ausência de protocolos, especialmente assim se aprende nos cursos de formação. A padronização de protocolos passa pela avaliação clínica de suas vantagens, desvantagens, viabilidade e oportunidade de adoção a partir de metodologias bem estabelecidas na pesquisa com pacientes.

Na prática clínica ortodôntica do Brasil, quantos protocolos de documentação, diagnóstico e tratamento são adotados pelas sociedades, conselhos e órgãos regulamentadores?

Por exemplo, existe um documento formal, com acesso irrestrito de orientação minuciosa, de como deve ser uma pasta de documentação ortodôntica, emitido por alguma associação ou conselho que reune a grande maioria dos ortodontistas brasileiros? Neste documento constaria tamanhos de pastas, fotografias, impressos como 
ficha clínica e traçados. Ou ainda, como montar as fotografias, as radiografias e quais minimamente deveriam estar presentes no pasta, especialmente as periapicais. Constaria também um modelo de um laudo radiográfico, modelo de planejamento do tratamento, etc.

Cada centro de documentação ortodôntica segue um protocolo, mas como, qual o critério ou pesquisa em que cada centro de documentação e/ou centro ortodôntico se baseou para determinar a sua própria forma de fazer?

Quantas pastas de documentação no Brasil seguem as recomendações do conselho estadunidense de Ortodontia e/ou de outras organizações e fundações?

Qual é o nível percentual de padronização das documentações ortodônticas no país?

Se houvesse um protocolo de documentação que incluísse a análise de radiografias periapicais prévias como determinante e como item indispensável, os problemas durante o tratamento ortodôntico e que verdadeiramente seriam pré-existentes, necessariamente deixariam de ser "conseqüências" atribuídas ao mesmo, como por exemplo: reabsorções internas, anquilose alvéolo-dentária, reabsorção por substituição, reabsorção cervical externa, necrose pulpar e lesão periapical. Estas situações mencionadas não tem relação etiopatogênica com o tratamento ortodôntico, mas freqüentemente são atribuídas e aceitas como tal, por falta de documentação para determinar que estes problemas pré-existiam, mas em geral denota-se a falta de radiografias periapicais prévias.

Imaginando: como seria a prática ortodôntica se todas documentações seguissem um padrão nacional, incluindo-se, obrigatoriamente, as radiografias periapicais prévias de todos os dentes?

Não seria a hora de pensarmos nisto, pesquisando as vantagens e desvantagens; a oportunidade e a conveniência destas radiografias periapicais prévias; a gravidade e o percentual de reabsorções dentárias durante o tratamento.

Seria muito bom para os pacientes, para os profissionais e centros de documentação; a Ortodontia brasileira avançaria em qualidade e competência.

Quando as radiografias periapicais prévias, ainda assim, impossibilitarem um definição segura do diagnóstico e prognóstico de reabsorções dentárias no planejamento ortodôntico, pode-se usar, de forma segura biologicamente e economicamente acessível, a tomografia computadorizada volumétrica ou de feixe cônico. No próximo número abordaremos este assunto. Hoje, para a realização da TC volumétrica, inicialmente denominada TC odontológica, existem vários aparelhos no mercado, propiciando serviços a custos acessiveis, alguns dos quais com elevado grau de portatibilidade em seu design final.

Professor Titular em Patologia Bucal na Faculdade de Odontologia de Bauru (Graduação e Pós-Graduação) e na Pós-Graduação da Faculdade de Odontologia de Ribeirão Preto - Universidade de São Paulo. E-mail: alberto@fob.usp.br. 